Estudios de la Paz y el Conflicto

Revista Latinoamericana

IUDPAS-UNAH

Número Especial 1, pp. 102-110

ISSN-e: 2707-8922 / ISSN: 2707-8914

DOI: $10.5377 /$ rlpc.v0i0.9506

Anual 2019

\title{
PRÁCTICAS DE PAZ EN EL JARDÍN DE NIÑOS NENTAMBATI
}

\author{
PEACE PRACTICES IN NENTAMBATI KINDERGARDEN
}

\author{
Rosa María Medrano Domínguez \\ Supervisora, Supervisión Escolar J230 \\ rosymed07@hotmail.es \\ María Verónica de León Gutiérrez \\ Directora, Jardín de niños Nentambati \\ veroabril70@hotmail.com
}

Cómo citar / citation

Medrano, R. y de León, M. (2019). "Prácticas de paz en el jardín de niños Nentambati", Estudios de la Paz y el Conflicto, Revista Latinoamericana, Número Especial 1, 102-110.

DOI: $10.5377 /$ rlpc.v0i0.9506

\section{Resumen}

El aporte principal de este articulo son propuestas de prácticas de paz a partir del diagnóstico escolar, derivado de la investigación acción participativa. En las prácticas de paz el diálogo es detonador de mediación, diálogo entendido como la herramienta fundamental para transformar los conflictos.

En consonancia los actores educativos del Jardín de Niños Nentambati a través de su participación en la investigación se formaron en la lógica sentípensante, al descubrir relaciones pacíficas y violentas. Coparticipar en la gestión pacífica de los conflictos y favorecer la convivencia escolar a través de su actuación en las prácticas de paz, al ser la escuela el espacio de vínculos, en donde se espera que los alumnos además de alcanzar el logro de habilidades cognitivas, desarrollen habilidades sociales y emocionales que les permitan establecer relaciones armónicas, pacíficas e inclusivas dentro y fuera de ésta.

\section{Palabras clave}

Diagnostico; Relaciones pacíficas y violentas; Prácticas de paz; Diálogo.

\section{Abstract}

The main contribution of this article are proposals for peace practices based on the school diagnosis, derived from participatory action research. In peace practices, dialogue is a 
trigger for mediation, a dialogue understood as the fundamental tool for transforming conflicts.

In line with the educational actors of the Nentambati Kindergarten through their participation in the investigation, they were formed in the sentient logic, discovering peaceful and violent relationships. To participate in the peaceful management of conflicts and to favor school coexistence through their performance in peace practices, as the school is the link space, where it is expected that students, in addition to achieving the achievement of cognitive skills, develop social and emotional skills that allow them to establish harmonious, peaceful and inclusive relationships inside and outside it.

\section{Keywords}

Diagnosis; Peaceful and violent relationships; Peace practices; Dialogue.

\section{INTRODUCCIÓN}

Años atrás se pensaba que la educación era enseñar lo cognitivo, lo conceptual y lo procedimental enfocándonos más a lo cognitivo. Sin embargo, es tiempo de cambiar la forma de pensar y practicar la educación, debido a que la realidad cambia de manera constante.

En la actualidad es usual que algunas alumnas y alumnos, formen parte de una escalada de intolerancias hacia las diferencias culturales, al tiempo que viven en medio de expresiones de corrupción, discriminación e injusticias en sus distintos entornos; acciones que provocan conflictos de manera constante entre la comunidad educativa (estudiantes y sus familias, profesores/as, personal de apoyo a la educación y directivos), quienes llegan a ver en la violencia la medida inmediata a conflictos y problemas (Salazar, 2013).

Vivimos inmersos en la cultura de la violencia escolar, como lo expresan las noticias que leemos y vemos a diario sobre el acontecer local, regional e internacional. Derivado de ello, "algunas noticias muestran que la sociedad mexicana está alarmada por el giro que sufren ciertas instituciones educativas en el país, al ser vistas como lugares donde la violencia tiene lugar y se incrementa de manera constante" (Salazar, 2013:1). Sin embargo:

"ante esta realidad escolar violenta, la forma tradicional de actuar frente al conflicto ha sido a través de la sanción disciplinaria, pero no siempre el castigo supone un cambio de la conducta. Si bien resulta importante que se intervenga para dar solución a los conflictos y violencias entre estudiantes, también es de suma importancia que se reconozcan las actitudes violentas manifestadas por los agresores, la vulnerabilidad de los agredidos, la pasividad y el conformismo de los testigos" (Salazar, 2013: 1).

De acuerdo con los conflictos y violencias escolares antes descritas, el presente artículo intenta mostrar, con testimonios y evidencias, la pertinencia de la implementación de prácticas de Paz como una alternativa para transformar la realidad.

Dentro del aula escolar hay alumnos con características únicas que los hacen diferentes, por lo que cada institución tiene la prioridad de educar para la diversidad, sin embargo, cada persona tiene ideologías y comportamientos que son generadores de conflictos interpersonales, con escenarios desfavorables que afectan el clima escolar y, como consecuencia, no se adquiere un aprendizaje significativo en su totalidad.

En las instituciones educativas crece la problemática día a día y se generan secuelas en el alumno que es agredido, así como en el agresor, el cual presenta consecuencias a largo plazo Estudios de la Paz y el Conflicto, Revista Latinoamericana, IUDPAS-UNAH, Número Especial 1, 2019, pp. 102-110. DOI: $10.5377 /$ rlpc.v0i0.9506 
cuando trata de interactuar con la sociedad, puesto que es rechazado y constantemente se encuentra solo por la falta de control de sus impulsos, entre otro tipo de situaciones que afectan su personalidad.

Por tal situación la escuela es fundamental al ser concebida como el espacio de vínculos, en donde se espera que los alumnos además de alcanzar el logro de habilidades cognitivas, desarrollen habilidades sociales y emocionales que les permitan establecer relaciones armónicas, pacíficas e inclusivas dentro y fuera de ésta. Enseñar y aprender a convivir constituye uno de los pilares de la educación, por lo que la escuela como parte de su función social puede contribuir decididamente a consolidar este aprendizaje. Al analizar el concepto sobre convivencia se reconoce que: las instituciones escolares constituyen el lugar idóneo en el que enseñar a convivir al alumnado $\mathrm{y}$, por ende, dotarles de las habilidades sociales necesarias que contribuyan a su pleno proceso de desarrollo social y personal (Ramírez y Justicia, 2006). El desarrollo de habilidades sociales y emocionales se transforma en una oportunidad para la escuela, a fin de contribuir al fortalecimiento personal y al funcionamiento social de los alumnos, en tanto que favorecen la autoestima y la identidad; la autorregulación de las emociones e impulsos; el respeto de las reglas; el manejo y la resolución de conflictos y al establecimiento de relaciones inclusivas, armónicas y pacíficas.

En este sentido la convivencia es una condición para el aprendizaje porque influye en la tarea pedagógica que se desarrolla en la escuela. La convivencia escolar por lo tanto es una responsabilidad de quienes conforman la comunidad educativa en su conjunto; por lo que su mejora exige la participación de alumnos, docentes, personal directivo, personal de apoyo, madres, padres y tutores

Fortalecer la convivencia escolar no solo depende de los docentes dentro del aula, sino de los padres de familia, los directivos y la cooperación continua de los alumnos inscritos en cada institución, lo que resulta una situación compleja, por lo que es primordial diseñar prácticas de paz con la finalidad de contribuir a una convivencia en beneficio de una cultura para la paz, por lo tanto, el apoyo mutuo es la clave para fortalecer las relaciones entre alumnos.

Para prevenir y tratar la violencia escolar es necesario que las prácticas de paz estén vinculadas con la educación dentro del aula, que esta fomente la educación para la paz, en la cual están inmersos los valores de respeto y tolerancia en las relaciones interpersonales, por esto se pretende crear una nueva conciencia en donde se viva la regulación de las emociones y la práctica de la paz de manera permanente.

Es el objetivo del Jardín de Niños, Nentambati: crear espacios de reflexión para generar nuevas formas de convivencia dentro del aula y fuera de ella. Durante tres ciclos escolares anteriores y hasta el día de hoy, bajo esta premisa se han implementado prácticas de paz para aminorar las conductas agresivas en el alumnado tanto en el aula como fuera de ella.

\section{MÉTODOLOGÍA}

Cabe señalar que las prácticas de paz en esta escuela surgen del diagnóstico en el cual se detecta a los alumnos que se relacionan de manera violenta. Tanto el diagnóstico como la planeación y las prácticas de paz se implementan bajo la metodología cualitativa y el método investigación acción participativa.

Cómo se explicó con antelación, el método a utilizar en esta investigación es la Investigación Acción Participativa, entendida como el proceso dialéctico continuo en el que

Estudios de la Paz y el Conflicto, Revista Latinoamericana, IUDPAS-UNAH, Número Especial 1, 2019, pp. 102-110. DOI: $10.5377 /$ rlpc.v0i0.9506 
se analizan los hechos, se conceptualizan los problemas, se planifican y se ejecutan las acciones en procura de una transformación de los contextos, así como los sujetos que forman parte de los mismos (Fals Borda, 1986), con la finalidad de implementar acciones de acuerdo con los hallazgos.

\section{PRÁCTICAS DE PAZ}

A continuación, se presenta la práctica de paz que se ha implementado en el Jardín de Niños Nentambati:

\section{Recreo Interactivo}

En el Jardín de Niños se implementó el recreo interactivo organizado por rincones de juegos, se instalaron en el patio en donde los alumnos pudieran convivir con sus compañeros de diferentes edades y a su vez aprendieran a respetarse, compartir y convivir. Se hace mención de los rincones: futbol, baile, muñecos, construcción, juguetes tradicionales y carros.

Medrano, define el recreo Interactivo como la "propuesta que permite a las niñas y a los niños actuar bajo un ideario de valores que a su vez les posibilite abrir espacios de reflexión y concientización de sus actos, logrando con ello aminorar los conflictos que se susciten en el recreo y mejorar los ambientes de aprendizaje. Se organiza mediante la colocación de juegos en el patio en el tiempo de recreo. Pretende favorecer las relaciones interpersonales, los ambientes de convivencia, disminuya las agresiones físicas y verbales. Se eviten accidentes involuntarios y actos de violencia en la etapa preescolar (Siendo respuestas impulsivas por la falta de regular sus emociones como características propias de la edad)" (Medrano, 2017: 91). La convivencia no ha de entenderse sólo como la ausencia de violencia, sino principalmente como el establecimiento de relaciones interpersonales que contribuyan a un clima de confianza, respeto y apoyo mutuo en la institución escolar (Ortega, 2007).

En el presente ciclo escolar 2019 - 2020 se llevó a cabo la inauguración del Recreo Interactivo en el Jardín de Niños Nentambati, en el cual fue pronunciado el siguiente discurso de la directora escolar:

"Buenos días autoridades educativas, padres de familia, docentes y alumnos. hoy nos encontramos reunidos para llevar a cabo la inauguración del recreo interactivo y el de palabras de cortesía, cuyo objetivo principal del Jardín de Niños Nentambati es lograr que los alumnos convivan de manera armónica con sus compañeros en las diferentes actividades en el aula y fuera de ella y lo que deseamos es que trasciendan los muros escolares para manifestarse en los diferentes espacios de vida de los alumnos (la calle, el hogar, el trabajo y la comunidad en general), es lo que anhelamos como escuela. Esto está sustentado en los lineamientos de autonomía de gestión curricular y de la autonomía curricular de las escuelas en donde nos menciona: que la escuela debe establecer las condiciones para generar en la escuela una convivencia sana, pacífica e incluyente, basada en los valores de la democracia y el respeto a los derechos humanos, así como implementar acciones para prevenir y erradicar todo tipo de violencia, el maltrato y el acoso en el centro escolar, es por ello que como escuela estamos al pendiente en buscar estrategias en que nos apoyen a lograr una convivencia en toda la comunidad escolar y sobre todo el que formemos niños felices. Es por ello padres de familia, que el Jardín de Niños los invita por medio del ejemplo de ustedes, en un futuro podamos lograr formar ciudadanos respetuosos, responsables y sobre todo a que aprendan a convivir armónicamente con sus semejantes. Muchas Gracias" 
En la inauguración (figura 1) el alumnado de la institución presentó la organización de los seis rincones de convivencia, señalando el objetivo de cada uno:

a. Rincón de juguetes tradicionales: se rescata el uso de diferentes juguetes de la cultura mexicana y también se aprende a compartir los materiales con los amigos: Bruno

b. Rincón de Juguetes: se emplea el juego simbólico para representar situaciones mentales reales o ficticias y se aprende a convivir con los amigos: Estefanía

c. Rincón de Construcción: se favorece el desarrollo de la creatividad y el trabajo en equipo: Luna Zoe

d. Rincón de muñecos: se promueve la equidad de género y se aprende a respetar para convivir entre todos: Leonardo

e. Rincón de Futbol: se favorecen habilidades motrices básicas y se aprende a trabajar en equipo y a cuidarse entre todos. Asimismo, se atiende a la perspectiva de género en donde mujeres y hombres participan en el juego: Saúl

f. Rincón de Baile: se fortalece la expresión corporal y el sentido rítmico y se aprende a compartir los materiales: Valentina

\section{Figuras 1. Inauguración del recreo interactivo:}

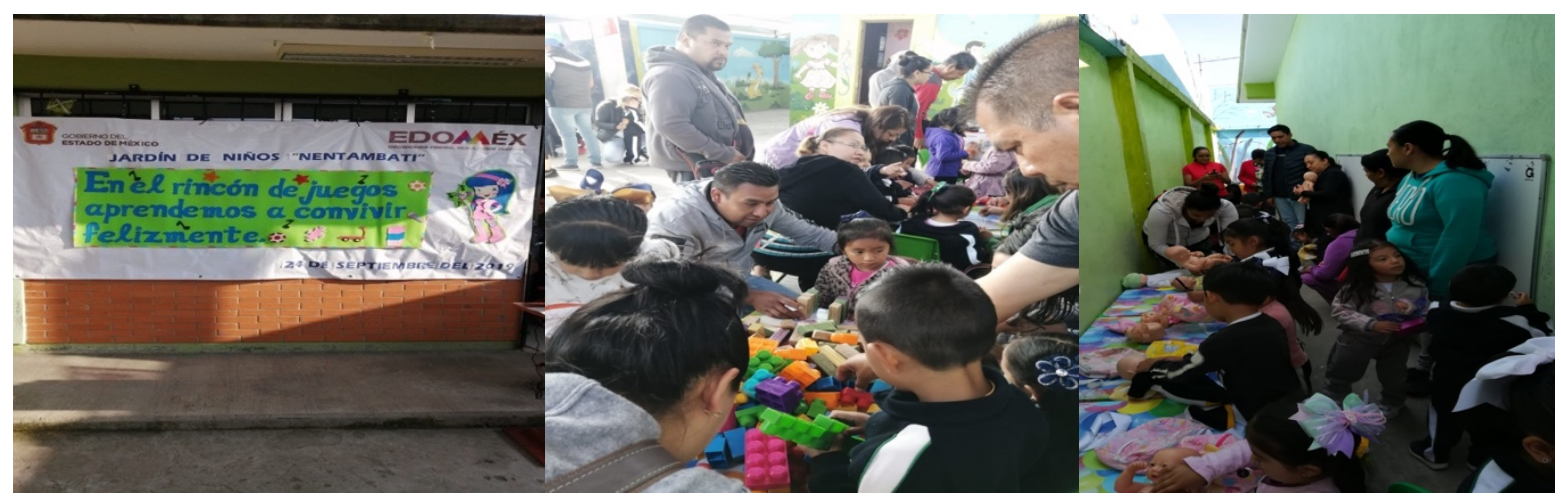

Cabe mencionar que al poner en práctica estos rincones se está atendiendo al factor de inclusión educativa, la cual se refiere a la atención a la diversidad de intereses, ritmos, capacidades y necesidades de aprendizaje del alumnado.

\section{OTRAS PRÁCTICAS DE PAZ}

A continuación, se presentan otras prácticas de paz que se han implementado en el Jardín de Niños para erradicar la violencia o en su caso aminorarla y favorecer la convivencia escolar.

\section{Rincón de los amigos}

Espacio para transformar los conflictos a través del dialogo. Está práctica propicia la reflexión sobre las conductas del alumnado con sus compañeros y se reúnen para poder solucionar y/o transformar conflictos, emplean palabras que les encanta escuchar como por ejemplo: perdón, por favor, ellos tienen que encontrar una solución para poder aprender a convivir de manera pacífica.

Estudios de la Paz y el Conflicto, Revista Latinoamericana, IUDPAS-UNAH, Número Especial 1, 2019, pp. 102-110. 
El testimonio de la Sra. Amanda Pichardo nos dio a conocer de manera general los logros observados en su hija a lo largo del ciclo escolar anterior y en donde se recupera la transformación de su hija en cuanto a la regulación de sus emociones.

"Durante el ciclo pasado en cada grupo se trabajó el rincón de los amigos observando que mi hija logró convivir de una forma pacífica no solo en su salón ni en la escuela, sino que también dentro del hogar y al integrarse con personas diferentes a quienes trataba con respeto, aprendió a comprender y manejar sus emociones, a tomar decisiones responsables reflexionando sobre las consecuencias de sus actos, claro en la medida de sus posibilidades, aprendió a cuidarse a sí misma, a trabajar en equipo, a compartir los materiales, a establecer acuerdos para resolver conflictos de manera pacífica y a ser más empática con los demás. En coordinación de papás y de maestras lograremos mejorar la convivencia de toda la comunidad escolar, lo cual representa un granito de arena para cambiar a nuestra sociedad".

\section{Acuerdos de convivencia}

La docente en consenso con sus alumnos establece acuerdos que les permitirán llevar a cabo una convivencia pacífica dentro del aula, esta práctica está fundamentada en (Medrano, 2017: 86).

"Son acuerdos consensuados por el alumnado y docente a fin de conocer sus derechos, responsabilidades y consecuencias, en caso de incumplimiento. Generan mecanismos de disciplina que sientan las bases por las que todos los alumnos y alumnas deben responder y comportarse en las distintas situaciones que suceden en la escuela y principal en el aula. Se establecen de forma democrática, se representan con dibujos o laminas y se colocan en un cartel o pizarrón para visualizarlos en todo momento y regular la convivencia escolar. Promueven la interacción en estudiantes y docentes con el fin de establecer procesos de enseñanza aprendizaje de contenidos y valores de manera adecuada y eficaz".

\section{Semáforo de conducta}

Práctica para ayudar a regular las emociones y evitar la violencia. Al término de la mañana de trabajo la educadora cuestiona a los alumnos ¿cómo fue su actuar durante las mañanas con sus compañeros? y ellos mismos analizan como se comportaron, posteriormente colocan la pinza con su imagen en el semáforo en la luz roja, amarilla o verde y participan sus compañeros ya que ellos también dan su punto de vista en el análisis de la conducta.

a. Luz roja: ALTO, tranquilízate y piensa antes de actuar.

b. Luz amarilla: PIENSA soluciones y sus consecuencias.

c. Luz verde: ADELANTE e implementa la mejor solución.

\section{Panal de conducta}

Esta práctica permite a los alumnos regular sus emociones para no molestar a sus compañeros, porque les gustaría ver volar su abeja, ya que si alguien molestaba a uno de sus compañeros su abejita tenía que estar en el panal hasta que le pidiera disculpas a su compañero y posteriormente saldría para poder volar otra vez, propicia la reflexión de su comportamiento ante los demás. 


\section{Ratoncitos de la conducta}

Esta práctica ayudó a que los niños reflexionaran sobre las consecuencias de sus actos, porque en el momento de que tuvieran una conducta que afectará a sus compañeros se le cortaba un pedazo de colita a su ratón esa era la consecuencia de su acto y a ellos no les gustaba que su ratón se quedara sin cola, por ello modificaban su conducta y se portaban bien para una mejor convivencia con sus compañeros.

\section{Jardín de la Conducta}

Esta práctica generó en los alumnos aprender a convivir con sus compañeros respetando los acuerdos de convivencia, porque cuando los alumnos no respetaban a sus compañeros en el jardín de la conducta se le quitaba un pétalo a la flor y su flor se quedaría sin pétalos, es por ello que los alumnos lo mejor que hacen, es aprender a convivir entre todos para ver su jardín con flores. Los logros con dicha práctica fueron: fortaleció la comprensión de valores como el respeto, la honestidad, la responsabilidad, la amistad y la verdad; se mejoró la unión de la comunidad escolar y se favoreció la unión de grupo.

\section{Héroes de la conducta}

Esta práctica les gustó mucho a los alumnos porque tenían su capa de su héroe favorito, es por ello que al momento de salir al recreo salían con su capa para poder observar a sus amigos si se portaban bien y en caso de que hubiera una conducta inapropiada inmediato informaban a la maestra o ellos mismos platicaban con los niños para que modificaran su conducta por una acción positiva, fue una actividad muy novedosa y placentera para ellos ya que se sentían responsables al poder ayudar a sus amigos y evitar peleas.

\section{Palabritas de cortesía}

Esta práctica tiene la finalidad de resarcir la molestia con palabras de cortesía. En actividad a los alumnos se les enseña que en el momento de molestia se mencione, que les gustaría escuchar palabras como: perdón, discúlpame, gracias, por favor... y a través de la expresión se sienten mejor. Estás expresiones van acompañadas de un abrazo.

\section{Circuito practiquemos valores}

Esta práctica propicia la participaron de padres de familia, mediante cuentos, fabulas a los alumnos les explican lo importante que son los valores como: el respeto, tolerancia... porque nos permiten aprender a convivir con las personas, los niños participaban activamente cuando los padres de familia los cuestionan, fue una experiencia de aprendizaje para los alumnos, al reconocer la importancia de los valores.

\section{Campaña de valores}

Los alumnos con esta práctica pasaron a las aulas para dar a conocer a sus compañeros los valores, utilizando carteles como recurso didáctico para explicar. Enfatizan la importancia de 
respetar a sus amigos. Al termino del recorrido por las aulas, colocan los carteles en lugares estratégicos para que sean visibles por la comunidad escolar.

\section{Rally de valores}

Esta práctica reforzó la importancia de fomentar y practicar los valores como; el respeto, la colaboración, por ejemplo, en una acción un alumno tenía que apoyar a su compañero a pintar su cara de pirata, dicha actividad genero la reflexión sobre la pertinencia de apoyarnos y respetarnos. La práctica fue implementada por la promotora de salud.

\section{Pajaritos felices}

Esta práctica le agrado al alumnado al ver volar a los pajaritos y cuando ellos tenían una conducta que les molestara a sus compañeros lo que hacían era platicar entre ellos utilizando las palabras de cortesía, porque no quería que a sus pajaritos se les quitara una pluma ya que no podrían volar y se iban a entristecer.

\section{Ganando estrellas}

Práctica de paz que se implementa al final de la jornada de trabajo, la maestra cuestiona a los alumnos sobre cómo fue su comportamiento con sus compañeros en el aula y fuera de ella y comparten sus opiniones. A los alumnos que se relacionaron de manera pacífica, la maestra les otorga una estrella y ellos muestran felicidad al momento de colocarla en su nombre.

\section{REFLEXIONES FINALES}

Las situaciones de conflicto entre niños son frecuentes, tanto en casa como en la escuela. Es por ello que se sugiere a los padres de familia: "Si usted presencia un conflicto entre su hijo y un hermano, primo o vecino, intervenga en actitud conciliadora; sepárelos si están peleando y dé tiempo para que pongan en palabras sus sentimientos y expliquen la causa del; ayude a que propongan soluciones razonables. Lleguen a algún acuerdo y dé seguimiento para que se cumpla. Hacerlo así genera en ellos confianza hacia el adulto y aprenden a encontrar de solución" (SEP, 2018).

Las Prácticas de Paz implementadas en el Jardín de Niños Nentambati han contribuido a la mejora de habilidades sociales, de las relaciones interpersonales, del clima del centro y de la convivencia, esta última ha de entenderse, como la calidad de las relaciones interpersonales que se han construido en la institución y que dan lugar a un determinado clima escolar que, a su vez, influye sobre éstas. La búsqueda de una convivencia positiva se convierte, así, en una meta esencia de la educación, no debiendo entenderse exclusivamente como una reacción ante la aparición de determinados conflictos. 


\section{REFERENCIAS}

Fals Borda, O. (1986). La investigación-acción participativa: Política y epistemología. Bogotá: Cerec.

Medrano D.R. (2017). "La convivencia escolar desde prácticas de paz en el marco de la ruta de mejora, zona escolar J230, región Metepec, Estado de México". Tesis de doctorado en Educación para la Paz y la Convivencia Escolar. Universidad Autónoma Intercultural de Sinaloa. México.

Ortega, R. (2007). "La convivencia: un regalo de la cultura a la escuela", Revista Idea La Mancha, Número 4, páginas 50-54.

Ramírez, S. y Justicia, F. (2006). "El maltrato entre escolares y otras conductas-problema para la convivencia", Revista Electrónica de Investigación Psicoeducativa, Número 9, páginas 265-290.

Salazar, I.I. (2014). "Educación Intercultural para la Paz y la Convivencia Escolar en el Estado de México", Ra Ximhai, Vol. 10, Núm. 2, enero-junio, 2014. Universidad Autónoma Indígena de México.

SEP (Secretaría de Educación Pública) (2018). Educación Preescolar Libro para las Familias. México: SEP.

\section{REFERENCIA DE LAS AUTORAS}

Rosa María Medrano Domínguez: es Doctora en Educación para la Paz y la Convivencia Escolar por la Universidad Autónoma Intercultural de Sinaloa, y Doctora en Educación por el Instituto Universitario Internacional de Toluca. Acciones relevantes: participación en el Programa de Valores por una Convivencia Escolar, Diplomado en Convivencia y Prevención de la Violencia Escolar en Córdoba España, elaboración del manual para docentes mexiquenses "Aprender a Convivir en una Cultura de Paz", Implementación de Prácticas de Paz en la zona escolar J230 y Certificación Tutor de Formadores de Paz. Ha participado en congresos con temas en educación para la paz. rosymed07@hotmail.es

María Verónica de León Gutiérrez: es Maestra en Psicomotricidad. Ha trabajado en llevar a cabo prácticas de paz en la escuela en donde se ha fomentado la convivencia escolar. También se ha participado con las imágenes ilustrativas en donde los alumnos representan como han aprendido a convivir con sus compañeros en la revista Cópala Núm. 8. Cabe mencionar que también se ha dado a conocer en dos zonas escolares lo referente al recreo interactivo en donde a los alumnos aprenden a convivir en los diferentes rincones con niños de diferentes edades. veroabril70@hotmail.com

Recibido: 3-12-2019

Aceptado: 22-01-2020

(c) (i) Licencia Creative Commons Reconocimiento 4.0 (CC BY 4.0).

Estudios de la Paz y el Conflicto, Revista Latinoamericana, IUDPAS-UNAH, Número Especial 1, 2019, pp. 102-110. DOI: $10.5377 /$ rlpc.v0i0.9506 